\title{
Analysis of Load Optimization in Solid Rocket Motor Propellant Grain with Pressure Cure
}

\author{
Zhanxin Cui, ${ }^{1,2}$ Haiyang Li, ${ }^{1,2}$ Zhibin Shen $\mathbb{D}^{1,2}$ and Huiru Cui ${ }^{3}$ \\ ${ }^{1}$ College of Aerospace Science and Engineering, National University of Defense Technology, Changsha 410073, China \\ ${ }^{2}$ Hunan Key Laboratory of Intelligent Planning and Simulation for Aerospace Missions, Changsha 410073, China \\ ${ }^{3}$ College of Defense Engineering, Peoples Liberation Army Engineering University, Nanjing 210007, China
}

Correspondence should be addressed to Zhibin Shen; 17877783935@163.com

Received 18 May 2021; Accepted 11 September 2021; Published 27 September 2021

Academic Editor: Marco Morandini

Copyright (C) 2021 Zhanxin Cui et al. This is an open access article distributed under the Creative Commons Attribution License, which permits unrestricted use, distribution, and reproduction in any medium, provided the original work is properly cited.

At present, the casting of large-size motors often adopts pressure cure. This technology can effectively reduce the risk of damage to the structural integrity of the grain in the case-bonded casting solid rocket motor. In this paper, ABAQUS is used to establish a finite element model of star-shaped grains. The whole process of pressure cure was simulated and modeled, and the Python script was redeveloped. The Evol evolutionary algorithm was used in ISIGHT to optimize the load parameters such as pressure value, attenuation coefficient of the relief curve, and the attenuation coefficient of the cooling curve. The effects of different pressure values and different cooling and depressurizing rates on the residual stress and strain were analyzed. The optimization results show that the closer the pressure value is to the theoretical pressure, the more significant the effect of pressure cure. However, the effect of stress and strain reduction in different directions is slightly different. The different cooling and pressure relief rates have a great influence on the process quantity. Pressure cure works best when the pressure attenuation coefficient is equal to 6850 , and the temperature attenuation coefficient is equal to 8650 . The optimization analysis of pressure curing provides a reference for engineering practice.

\section{Introduction}

With the development of solid propellant technology, large thrust and large propellant loading ratio are required for the motor [1]. The application of pressure curing can effectively reduce the thermal stress and thermal strain of the motor during the propellant grain pouring process. The principle is that the propellant slurry is pressurized during the pouring process to make the motor case expand until the propellant grain solidifies. The pressure was reduced while lowering the temperature. The pressure compensates the shrinkage deformation caused by a temperature decrease, thus alleviating the limitation of the motor case on the shrinkage of grain. Equipment related to pressure cure is shown in Figure 1.

The survey results show that the relevant scholars in the United States [2], France [3], and Japan have carried out related research on pressure cure. The new technology is known to have been used in some models of the solid rocket motor in the United States. Arai [4] demonstrated the feasibility of pressure cure in the 20th century. It is proved that pressure cure can reduce the thermal stress and strain during curing and cooling without affecting the ignition. Zong et al. [5] calculated the theoretical pressure of pressure cure for different types of motor cases and proposed a simplified pressure cure simulation method. Liu et al. [6] derived a theoretical pressure cure formula for composite cases and verified that demoulding could be completed after pressure cure. Liang et al. [7] successfully carried out the ignition test of a pressure cure motor.

In order to accurately simulate the full process of pressure cure, the calculation is carried out in three steps during the simulation process. The first step of the analysis process assumes that the grain is a very elastic elastomer, and it can be assumed that the calculation is applied for a short period of time and that the pressure increases directly from 0 to the 


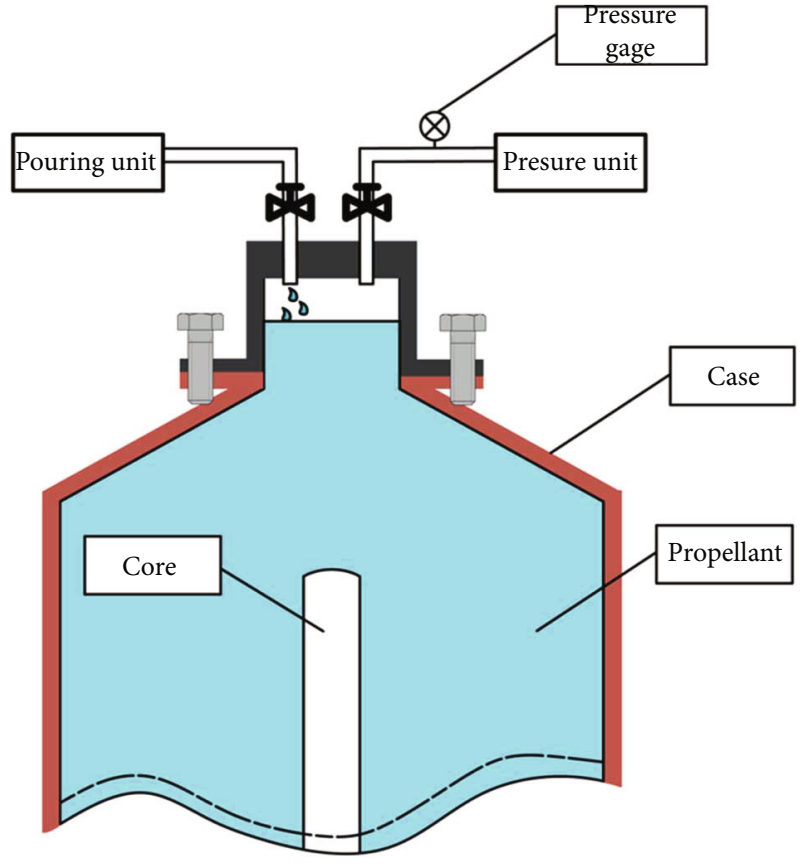

FIgURE 1: Equipment of pressure cure.

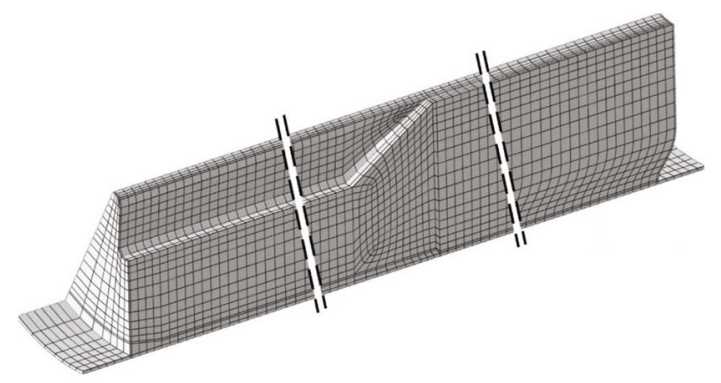

FIGURE 2: Finite element mesh of the solid rocket motor.

TABLE 1: Basic material parameters.

\begin{tabular}{lccc}
\hline Material parameters & Case & Insulation & $\begin{array}{c}\text { Cladding/ } \\
\text { propellant }\end{array}$ \\
\hline $\begin{array}{l}\text { Young's modulus, } E(\mathrm{MPa}) \\
\begin{array}{l}\text { Coefficient of thermal } \\
\text { expansion, } \alpha(1 / \mathrm{K})\end{array}\end{array}$ & 18600 & 60.1 & $E(t)$ \\
\begin{tabular}{l} 
Poisson' ratio, $v$ \\
\hline
\end{tabular} & 0.3 & 0.497 & 0.498 \\
\hline
\end{tabular}

designed pressure value. The second step is to keep the design pressure value unchanged and the drug grain to cure completely. In the third step, the pressure is reduced from the design pressure value to 0 , and the temperature is cooled from the curing temperature to the storage temperature. In this process, it is important to emphasize that the material properties of propellants need to be changed from elastic to viscous [8].
TABLE 2: The relaxation modulus prony series coefficient.

\begin{tabular}{lcccc}
\hline$n$ & 0 & 1 & 2 & 3 \\
\hline$\tau_{n}(\mathrm{~s})$ & -- & 5.56 & 55.6 & 555.6 \\
$E_{n}(\mathrm{MPa})$ & 5.9334 & 1.8925 & 1.3376 & 1.3309 \\
\hline
\end{tabular}

Pressure cure is still in the stage of technological exploration, and the process pressure can not meet the demand of theoretical pressure actually. At present, there is no unified standard for pressurization, pressure relief, and cooling, but the ultimate goal is to minimize the residual stress and strain in the propellant. In the process of simulation analysis, it is necessary to optimize the design of pressure value, pressure relief mode, and cooling mode, which will provide effective technical guidance for the subsequent development of the technology.

In this paper, ISIGHT optimization software by Dassault Company is used to analyze the load optimization problem. ISIGHT is a multidisciplinary platform [9]. Based on this software, the pressure and temperature load in the process of pressure cure of the motor propellant is analyzed in detail. The combination of this software, and ABAQUS is mostly used for structural optimization $[10,11]$. There are also cases of load optimization [12-14].

\section{Finite Element Modelling}

2.1. Model and Material Parameters. This paper mainly studies the interaction between the case and the propellant grain. A motor was selected to simulate the whole process of pressure cure. The motor is a simple star-shaped propellant grain. The front of the grain is cylindrical, and the back of the grain is star-shaped. It is a single-stage motor with case bounded.

The total length of the grain is $1600 \mathrm{~mm}$, the external radius of the grain is $100 \mathrm{~mm}$, and the inner radius of the grain $20 \mathrm{~mm}$. From the inside to the outside in turn is the grain, cladding, insulation, and case. Considering the temperature load symmetry, pressure load symmetry and geometric symmetry, $1 / 12$ of the original model was taken. The finite element model is shown in Figure 2. In order to ensure the accuracy of calculation, the number of elements should be guaranteed in the establishment of a 3D finite element model. The finite element model calculates a total of 27641 elements, all using hexahedral solid elements.

For the solid rocket motor mentioned above, the following assumptions are made before selecting material parameters:

(a) The propellant slurry is pressurized during the solidification stage. The propellant slurry is considered to be an approximately incompressible fluid. At this time, the propellant grain is considered to be a material with very small modulus and almost zero stress

(b) The cladding is very thin, and the material properties are similar to the propellant grains, which can be simplified to the same material 


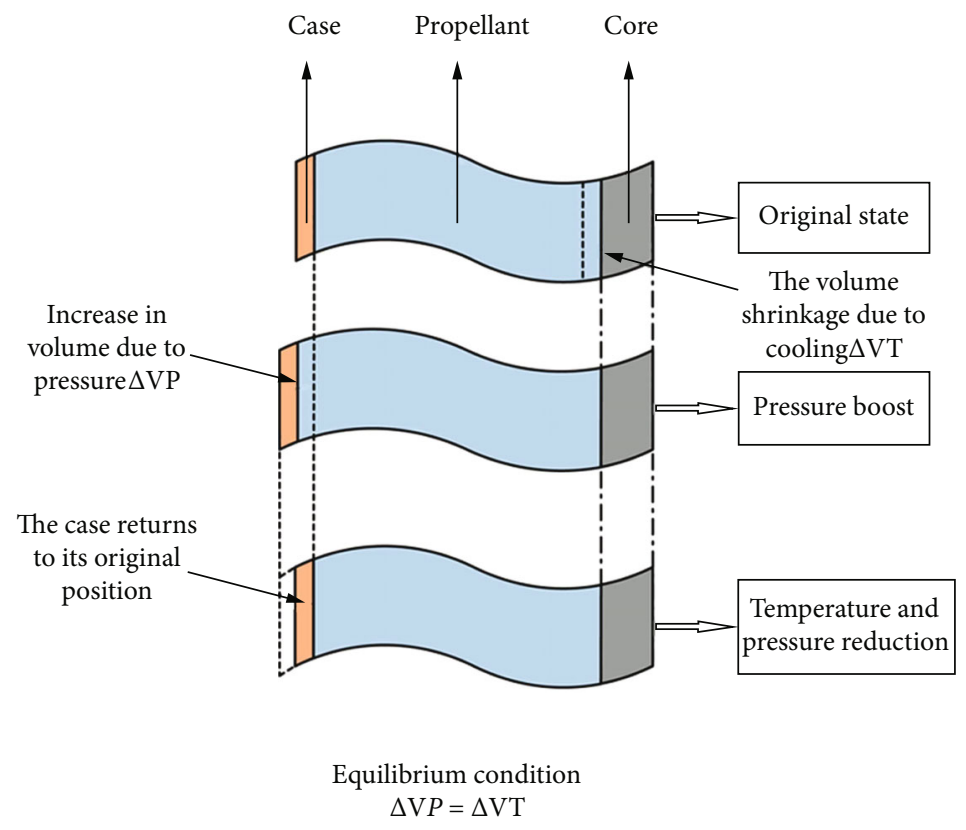

Figure 3: Principle of theoretical pressure calculation.

TABle 3: Parameters and interpretation.

\begin{tabular}{lcc}
\hline Parameter & Numerical & Explanation \\
\hline$L$ & $1600 \mathrm{~mm}$ & Axial length of the grain \\
$h$ & $1.6 \mathrm{~mm}$ & The thickness of the case \\
$R$ & $100 \mathrm{~mm}$ & External radius of the grain \\
$r$ & $20 \mathrm{~mm}$ & Inner radius of the grain \\
$E$ & $18600 \mathrm{MPa}$ & The elastic modulus of the case \\
$\alpha$ & $8.6 \times 10^{-5}$ & Coefficient of thermal expansion of the \\
& $1 / \mathrm{K}$ & grain \\
\hline
\end{tabular}

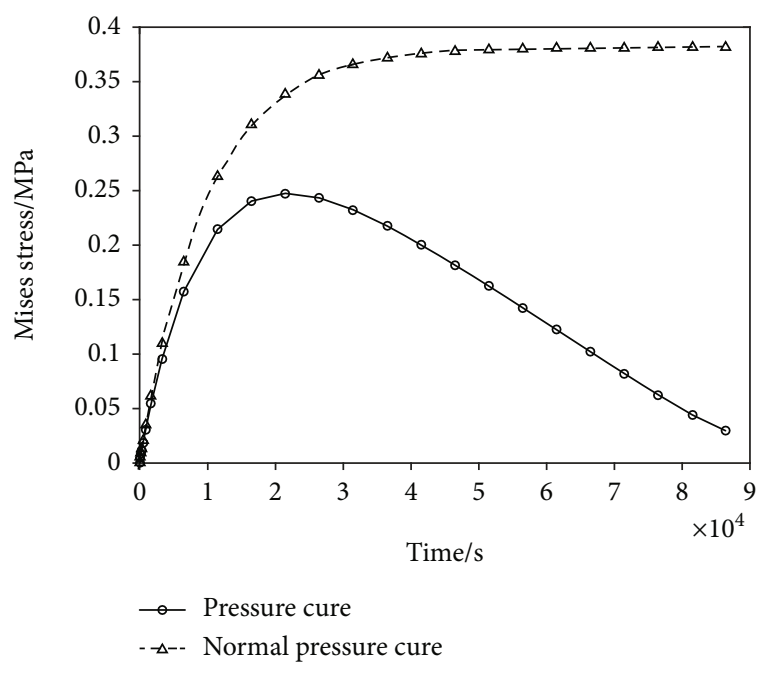

FIgURE 4: Mises stress time history diagram. (c) The shrinkage deformation caused by curing of a thermosetting material is approximately replaced by temperature compensation. According to experience, the zero stress temperature is increased by $8^{\circ} \mathrm{C}$ [15] relative to the curing temperature during calculation

(d) The motor case is assumed to be a uniform, less rigid elastic material. Prony series in the generalized Maxwell model is used to define the viscoelasticity of propellant grains [16]

Detailed material parameters are shown in Tables 1 and 2 .

The relaxation modulus is expressed as follows:

$$
E(t)=E_{\infty}+\sum_{n=1}^{N_{E}} E_{n} e^{-\xi / \tau},
$$

where $E(t)$ is the relaxation modulus, $n$ is the fitting coefficient, and $E_{\infty}$ is the equilibrium modulus.

\subsection{Load Analysis}

2.2.1. Theoretical Pressure Calculation. Combining the characteristics of the star tube motor model in this paper, it is simplified to a cylinder to calculate the theoretical pressure of pressure cure. For convenience of calculation, only propellant grain and case are considered here. The principle is shown in Figure 3. The position of the mandrel is fixed. The volume deformation caused by the outward expansion of the motor case under the pressure load $\Delta V_{p}$ is equivalent to that caused by the cooling of the solidified cylinder $\Delta V_{T}$. 


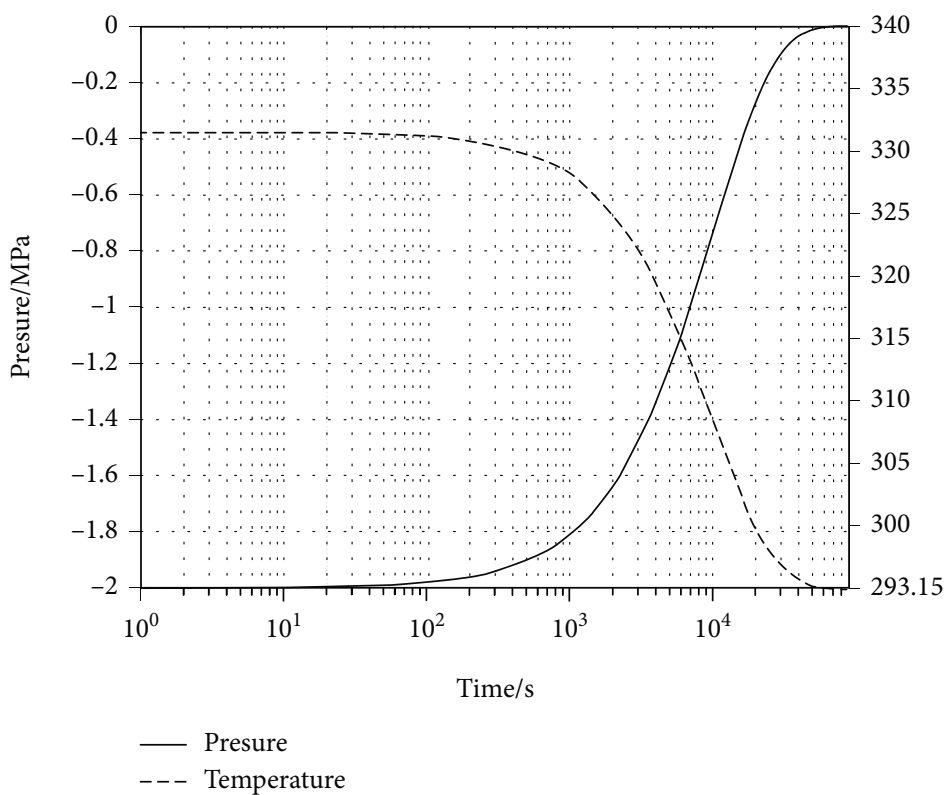

Figure 5: Load diagram for the cooling phase.

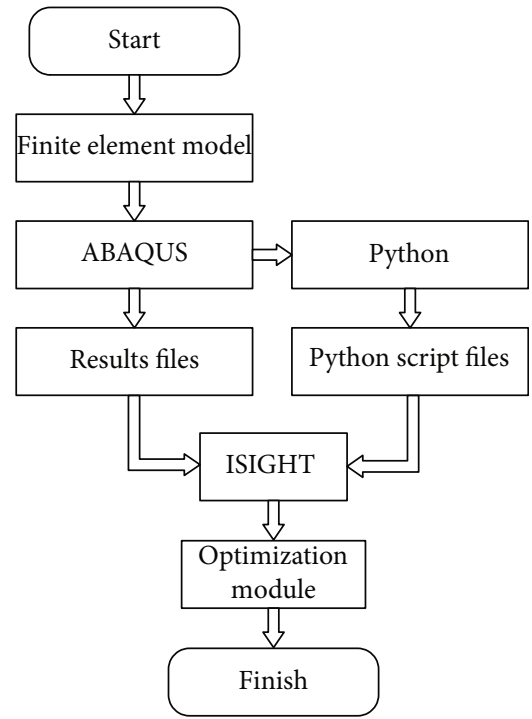

FIgURE 6: Structure analysis and optimization flow chart based on ISIGHT.

At this time, the pressure value is the theoretical pressure required by the pressure cure of the grain.

According to reference [5], the calculation formula is shown as follows:

$$
\begin{gathered}
\Delta V_{T}=3 \alpha \pi L\left(R^{2}-r^{2}\right) \Delta T, \\
\Delta V_{p}=2 \pi R \frac{P}{E h / R^{2}} L, \\
P=\frac{3 \alpha\left(R^{2}-r^{2}\right) E h \Delta T}{2 R^{3}} .
\end{gathered}
$$

Combined with the model parameters, the theoretical pressure of the model is about $1.4 \mathrm{MPa}$. Detailed model parameters are shown in Table 3.

2.2.2. Pressure Relief Curve and Cooling Curve. According to reference [5], the pressure value of the current pressure cure simulation analysis is linearly reduced to 0 . The decreasing mode of temperature generally shows a nonlinear attenuation trend. The Mises stress comparison diagram of the middle section of the propellant grain was obtained under the conditions of normal pressure cure and pressure cure.

In the structural integrity assessment of the grain, the stress and strain values at the end point are usually concerned. According to the data comparison in Figure 4, it can be clearly seen that the final stress after pressure cure is significantly less than that of normal pressure cure. It is proved that pressure cure can effectively reduce the residual thermal stress of the cylinder. However, the problem is that the final stress after pressure cure is far less than the extreme value of the stress in the calculation process. Therefore, only focusing on the final value is not accurate enough for structural integrity analysis, so it is necessary to design a reasonable relief curve to reduce the stress value in the process.

The ABAQUS decay amplitude curve was used as an example, and the definition formula for the curve was as follows:

$$
\begin{cases}Z=A_{0}+A \exp \left(\frac{-\left(t-t_{0}\right)}{t_{d}}\right), & \text { for } t \geq t_{0}, \\ Z=A_{0}, & \text { for } t<t_{0} .\end{cases}
$$

In combination with the changing rules of temperature 


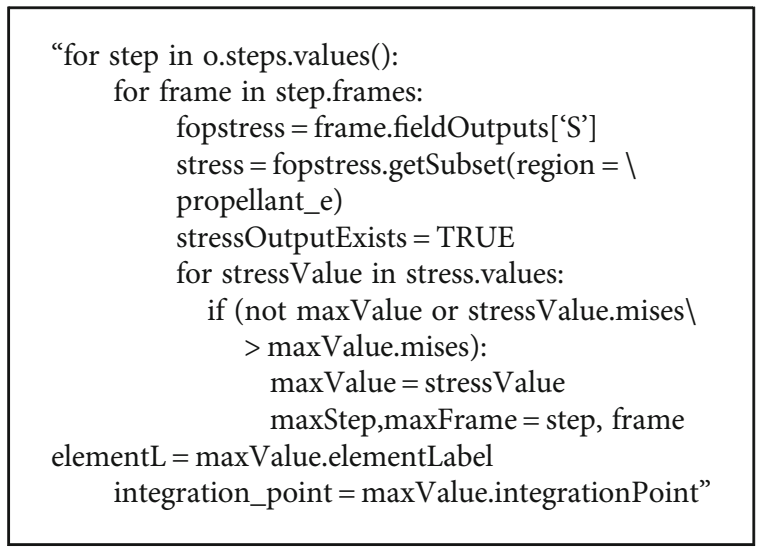

Algorithm 1

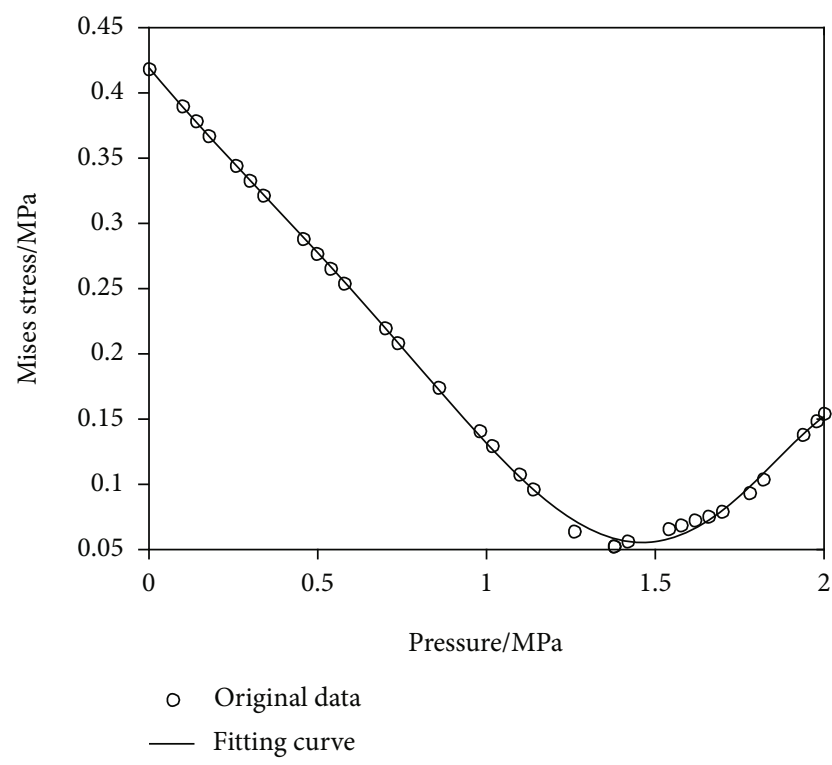

Figure 7: The variation of max Mises stress with pressure.

and pressure in the curing and cooling process, only the situation of the $t \geq t_{0}$.

Cooling curve:

$$
T=A_{T 0}+A_{T} \exp \left(\frac{-\left(t_{T}-t_{T 0}\right)}{t_{T d}}\right)
$$

The initial value is $t_{T 0}=0, t_{T d}=10000, A_{T}=38$, and $A_{T 0}=293.15$.

Pressure relief curve:

$$
P=A_{P 0}+A_{P} \exp \left(\frac{-\left(t_{P}-t_{P 0}\right)}{t_{P d}}\right) .
$$

The initial value is $t_{P 0}=0, t_{P d}=10000, A_{P}=-2$, and $A_{P 0}$ $=0$,

where $t_{T d}$ and $t_{P d}$ determine the curvature of the cooling and pressure relief curves. The following is collectively referred to as the attenuation coefficient of the cooling curve

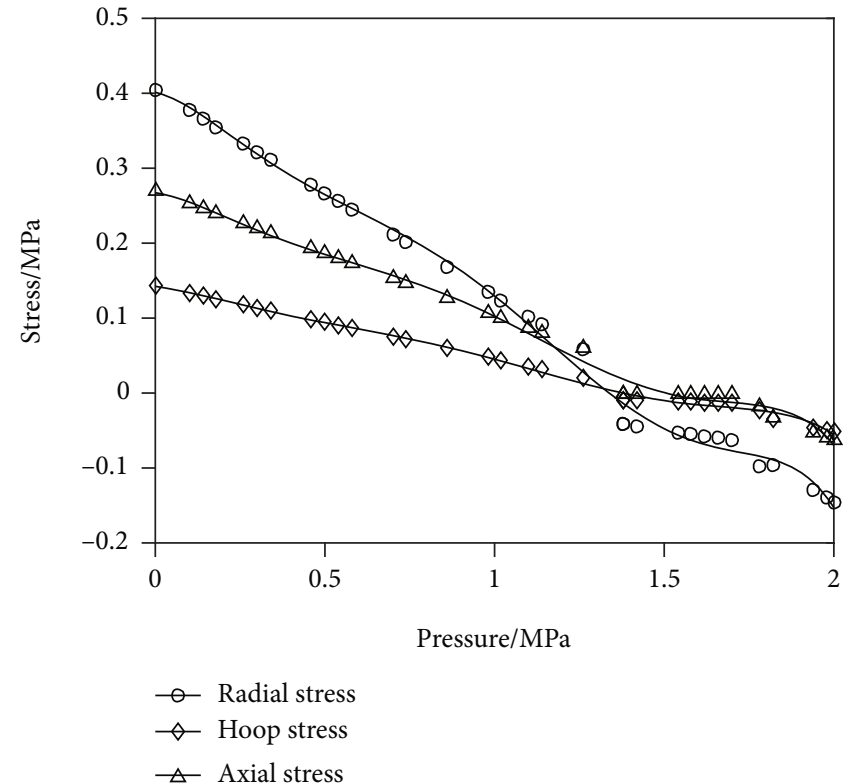

FIgURE 8: The trend of stress in three directions with pressure.

and the attenuation coefficient of the pressure relief curve. Taking the initial value as an example, the cooling and pressure relief curve are shown in Figure 5.

\section{Optimization Design and Results}

3.1. Secondary Developments of Pressure Cure Simulation Process. The optimization problem belongs to the optimization of load, mainly including curing pressure value, pressure relief method, and cooling method. For the sake of simplicity, the following are directly referred to as the pressure relief curve and the cooling curve. The objective is to minimize the residual thermal stress after curing and cooling. The specific optimization process is shown in Figure 6.

ABAQUS has three ways to execute commands: graphical user interface, command-line window, and script [17, 18]. Firstly, the whole process of finite element analysis should be based on ABAQUS platform and Python scripting language. Then load parameters such as the pressure value, attenuation coefficient of pressure relief curve, and attenuation coefficient of cooling curve were taken as the input of ISIGHT, and the code was rewritten to extract the stressstrain data from the result file into TXT file as the output of ISIGHT. The input, output, and execution steps of the application are integrated through the Sim Code module in ISIGHT.

Then, the corresponding optimization analysis is carried out with the optimization module. The Evol optimization algorithm [19] in global optimization was selected. An evolutionary optimization algorithm is an evolutionary strategy based on Rechenberg and Schwefel, which change the design by adding a normally distributed random value to each design variable. The variation intensity changes adaptively during the optimization process. 


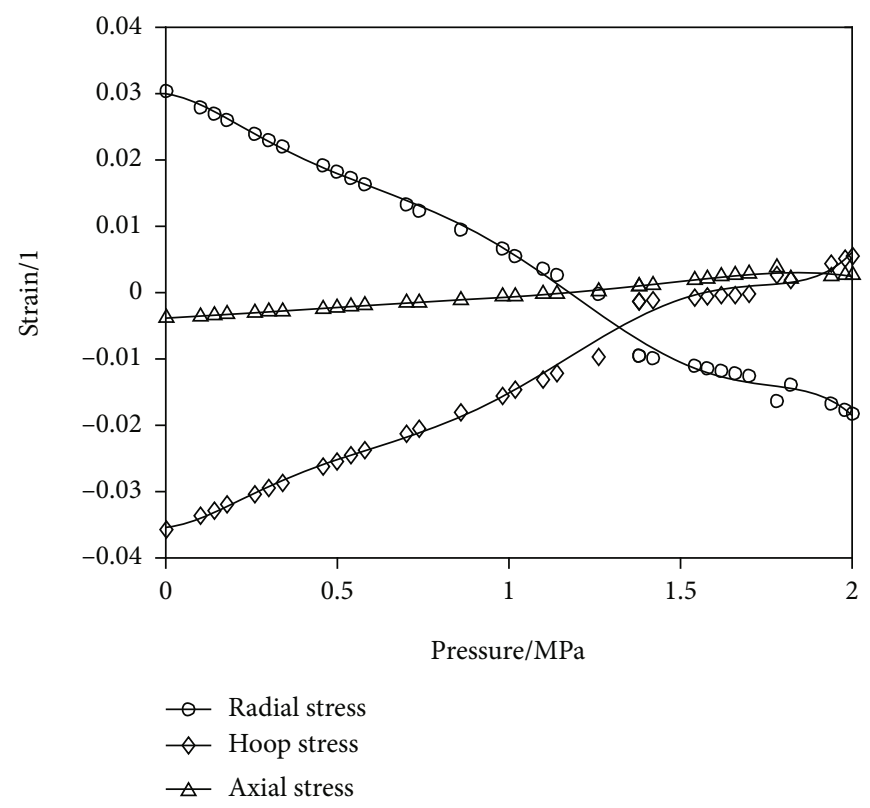

FIgURE 9: The trend of strain in three directions with pressure.

TABLE 4: Correlation analysis of max Mises stress.

\begin{tabular}{lc}
\hline Attenuation coefficients & Pearson correlation coefficient \\
\hline$t_{P d}$ & -0.5308 \\
$t_{T d}$ & -0.5204 \\
\hline
\end{tabular}

3.2. Sensitivity Analyses of Pressure Value. In the simulation analysis of the whole process of pressure cure, the initial values of the temperature drop and pressure relief curve remain unchanged, as shown in equations (6) and (7). Only the influence of the pressure value on the stress/strain curve is studied.

It can be known from the above calculation that the theoretical pressure is about 1.4 MPa. Here, the pressure value $P$ is taken as the input variable parameter in the range $[0,2]$. The maximum Mises stress point was used as the reference point for analysis. The objective of optimization is to minimize the stress/strain value after cooling is completed.

Since the structural integrity of the grain is mainly considered, the processing result here requires the change of stress. Only search elements in Set ['PROPELLANT']. The program sets the following:

"propellant_e $=$ o.rootAssembly.instances $\backslash$

[instanceL].elementSets['PROPELLANT']"

The algorithm 1 in the paper is to select the unit number of maximum Mises Stress and its integral point was selected by cycling.

Figure 7 shows the variation trend of the maximum Mises stress with the pressure value. It can be observed that the maximum Mises stress value is the smallest at about 1.4 MPa. It is shown that the effect of pressure cure is the best under this pressure value, consistent with the calculation above.
The stress calculation results are shown in Figure 8, which shows the trend chart of radial, hoop, and axial stresses changing with pressure values using different pressure values. When the radial stress is about $1.3 \mathrm{MPa}$, the maximum residual stress decreases to zero. When the circumferential stress is about $1.5 \mathrm{MPa}$, the maximum residual stress of the cylinder decreases to zero. When the axial stress is about $1.6 \mathrm{MPa}$, the maximum residual stress decreases to zero.

The strain calculation results are shown in Figure 9, which shows the trend chart of radial, hoop, and radial strains changing with pressure values using different pressure values. When the radial strain is about $1.3 \mathrm{MPa}$, the maximum residual strain decreases to zero. When the circumferential strain is about $1.4 \mathrm{MPa}$, the maximum residual strain decreases to zero. When the axial strain is about 1.2 $\mathrm{MPa}$, the maximum residual strain of the grain decreases to zero.

The overall variation trend of residual stress and strain curve is approximately linear. When the pressure value is close to $1.4 \mathrm{MPa}$, the final residual stress value is closer to zero; that is, the absolute value is the minimum. The overall trend has the opposite effect at $1.4 \mathrm{MPa}$. It is the same with the results of related literature and theoretical analysis.

\subsection{Sensitivity Analyses of Pressure Relief Curve and Cooling} Curve. The simulation results show that different pressure relief curves and cooling curves do not affect the final residual stress and strain of the propellant grain but have an effect on the stress and strain in the process.

Therefore, it is necessary to consider whether the stress and strain in the cooling process of the grain will be too large, or the mutation will be rapid. Therefore, the absolute value of the maximum Mises stress time history curve was 


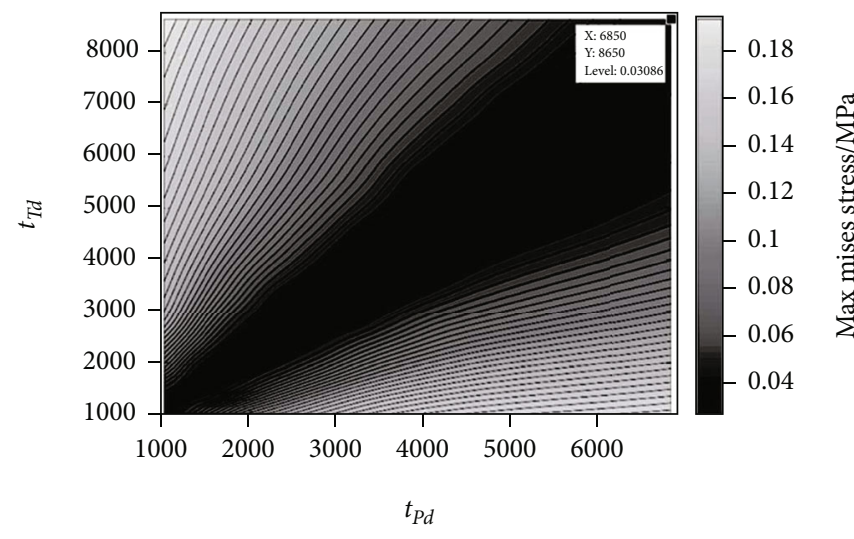

FIgURE 10: Relationship between design variables and target variables.

taken as the optimization objective parameter, and the temperature attenuation coefficient $t_{T d}$ and pressure attenuation coefficient $t_{P d}$ are taken as the design variables. The value range is $[1000,10000]$. Running the calculation 100 times, when these two values exceed this range, the temperature and pressure values can no longer be reduced to the specified values, which do not match the actual situation.

The correlation between pressure (temperature) attenuation coefficient and maximum Mises stress were obtained by analysis. Table 4 shows the Pearson correlation coefficient between the two variables and the design variables, which is between -1 and 1 . The simple correlation coefficient here measures the linear relationship between two variables. Both pressure attenuation coefficient and temperature attenuation coefficient were negatively correlated with max Mises stress. The correlation between the two indexes and max Mises stress was -0.5308 and -0.5204 .

The relationship between the target variable maximum Mises stress and the design variables $t_{P d}$ and $t_{T d}$ was calculated. It can be seen from Figure 10 that the minimum stress is at $\left[t_{P d}, t_{T d}\right]=[6850,8650]$ and the Mises stress is $0.03086 \mathrm{MPa}$.

It is obvious that there is a region where the value of the target variable is maintained around $0.0308 \mathrm{MPa}$. At the same time, there is a linear relationship between the two design variables. The relationship between $t_{P d}$ and $t_{T d}$ was obtained by linear fitting of the data points in this region. The fitted curve is shown in Figure 11.

According to the fitting results, the concern can be expressed by the following linear relationship.

$$
t_{P d}=1.18552 t_{T d^{-}}-126.22911 .
$$

3.4. Simulation Verification of Optimization Results. According to the optimized conclusion above, the value of the design variable corresponding to the minimum value of maximum Mises stress was selected. The pressure attenuation coefficient and temperature attenuation coefficient are as follows: $\left[t_{P d}, t_{T d}\right]=[6850,8650]$. The mechanical responses under the same time course of normal pressure cure and pressure cure before optimization and after optimi-

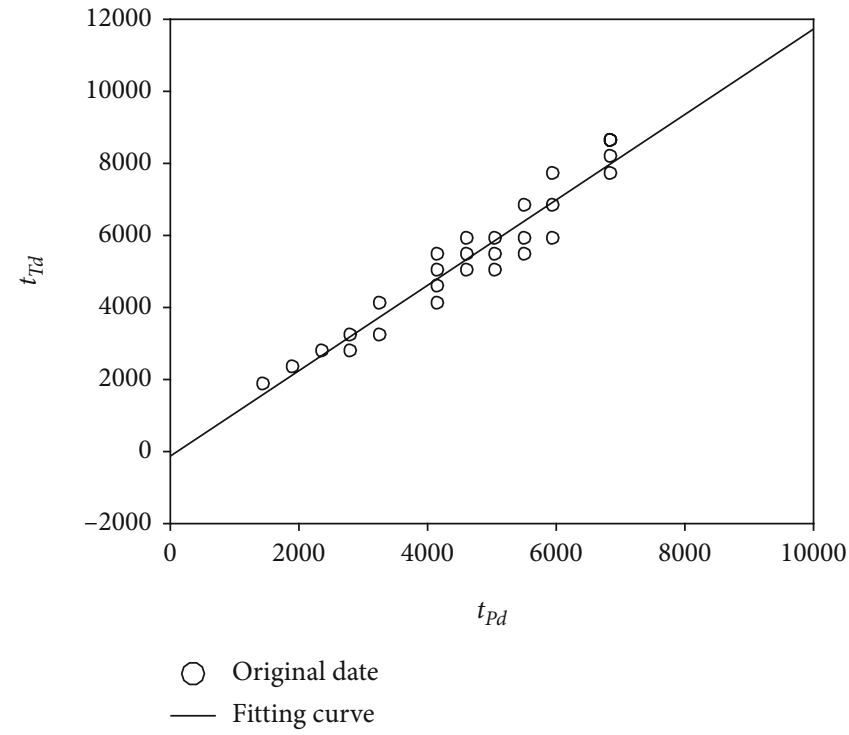

Figure 11: Linear fitting of data.

zation were compared under the middle position of the inner hole of the grain.

As showing in Figure 12, the Mises stress distribution nephogram after the completion of curing and cooling in the three states showed that the stress in the middle of the round tube section of the propellant grain was significantly reduced by pressure cure.

For this model, the maximum stress of the propellant grain is located in the middle of the circular tube section under atmospheric pressure cure, and the maximum stress of the propellant column is located in the star hole at the tail of the propellant column after pressure cure. It shows that the application of pressure cure can effectively reduce the residual stress in the round tube section and the transition section of the grain, the effect of pressure cure for different positions of the reduction effect is different. The optimized residual stress level of the grain star tube can be significantly reduced. This proves that optimization is meaningful. 


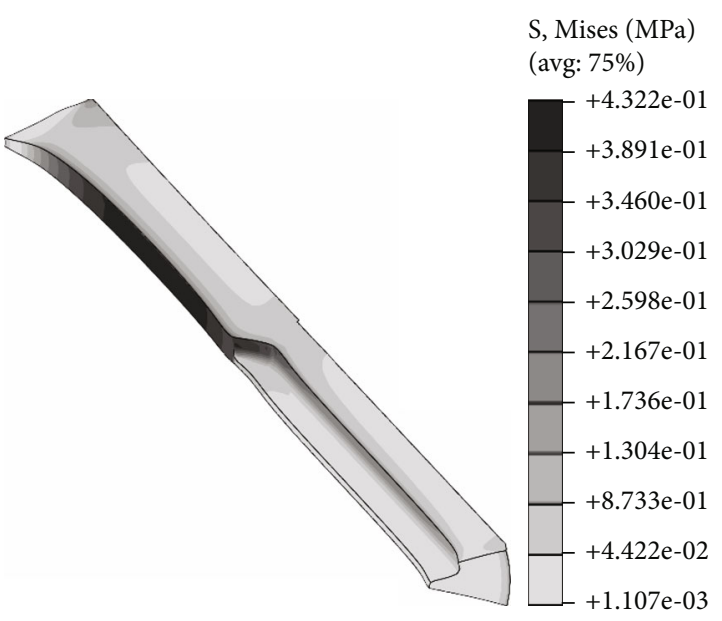

(a) Normal pressure cure

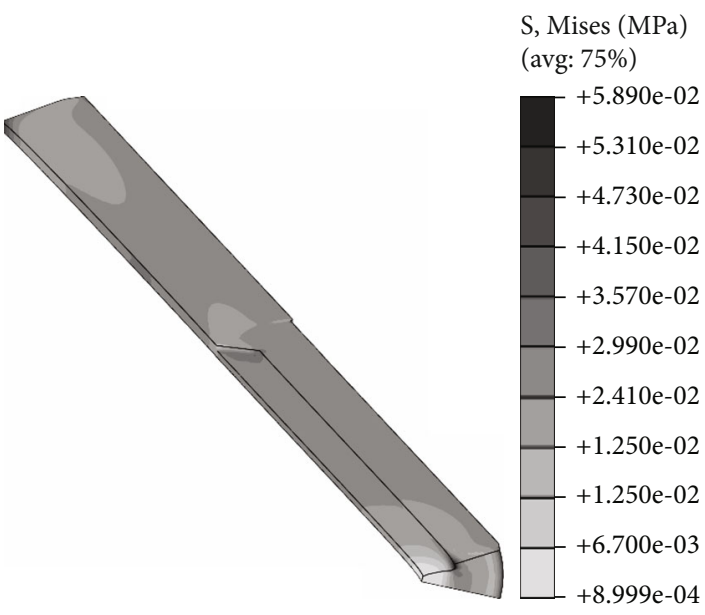

(b) Pressure cure before optimization (avg: $75 \%$ )

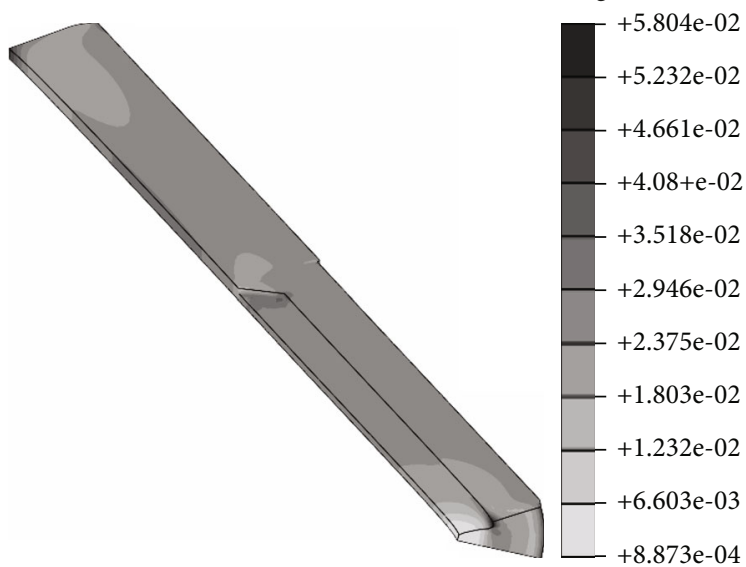

(c) Pressure cure after optimization

Figure 12: Mises stress nephogram.

Figure 13 shows the variation curve of the stress in three directions with time during the cooling process of the propellant grain.

From the final value, it can be found that the pressure cure can effectively reduce the residual stress of the grain. The radial stress reduction effect reached $95.67 \%$. The effect of hoop stress reduction reached $95.66 \%$. The axial stress reduction effect reached $87.20 \%$.

By comparing the pressure cure data before and after optimization, it is found that the optimization of pressure relief curve and cooling curve has no effect on the final residual stress value, and the final residual stress value is only related to temperature difference and pressure difference. However, the optimization can effectively reduce the extreme stress value in the process. The curve gets smoother. It reduces the risk of local damage caused by excessive stress in the cooling process.

Figure 14 shows the time variation curve of the strain in three directions during the cooling process of the propellant grain.
From the final value, it can be found that the pressure cure can effectively reduce the radial and hoop residual strains of the grain. The radial strain reduction effect reached $86.39 \%$. The effect of hoop strain reduction reached $80.99 \%$. The axial strain changes from the tensile strain ratio to compressive strain. The main reason is that the motor case does not wrap the front and rear end faces of the grain, which leads to its free contraction. The numerical order of magnitude itself is in the tens of thousands place. Compared with the strain in other directions, this effect can be ignored. The conclusion that the effect of pressure cure is significant still held.

By comparing the pressure cure data before and after optimization, the optimization of pressure relief curve and cooling curve have no effect on the final residual strain value. Same trend after stress optimization was observed. After optimization, the stress extremum in the process can be effectively reduced. The curve changes more gently. 


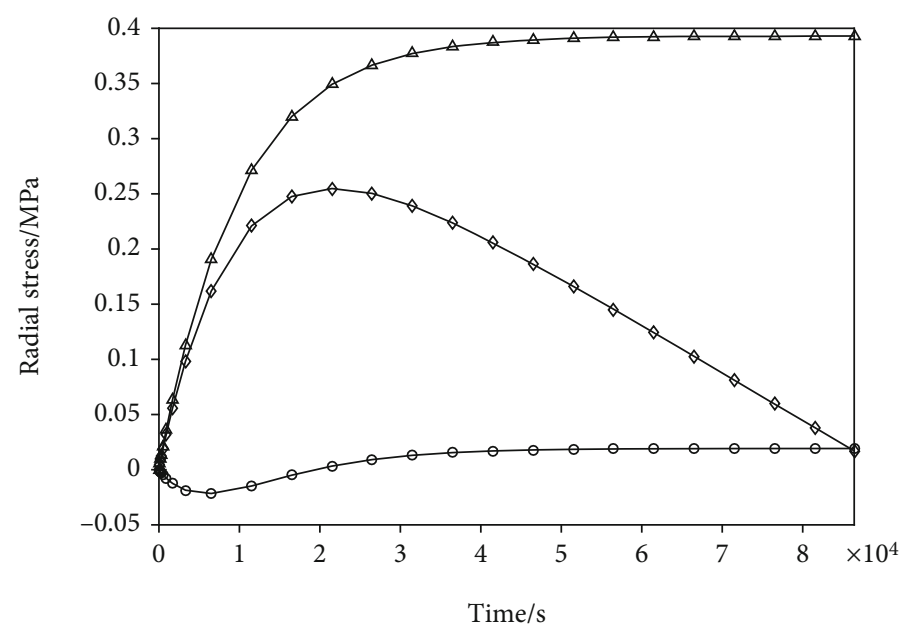

(a) Radial stress

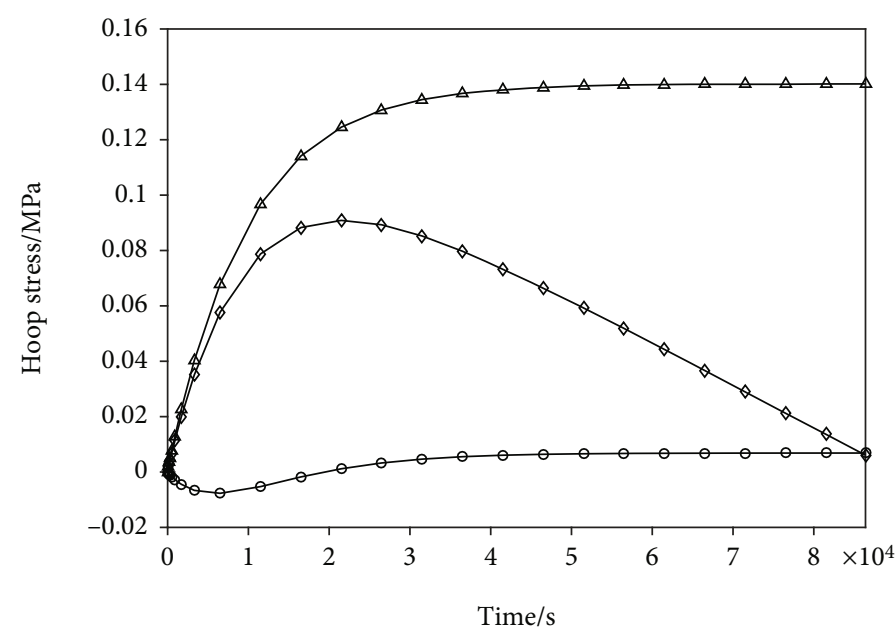

(b) Hoop stress

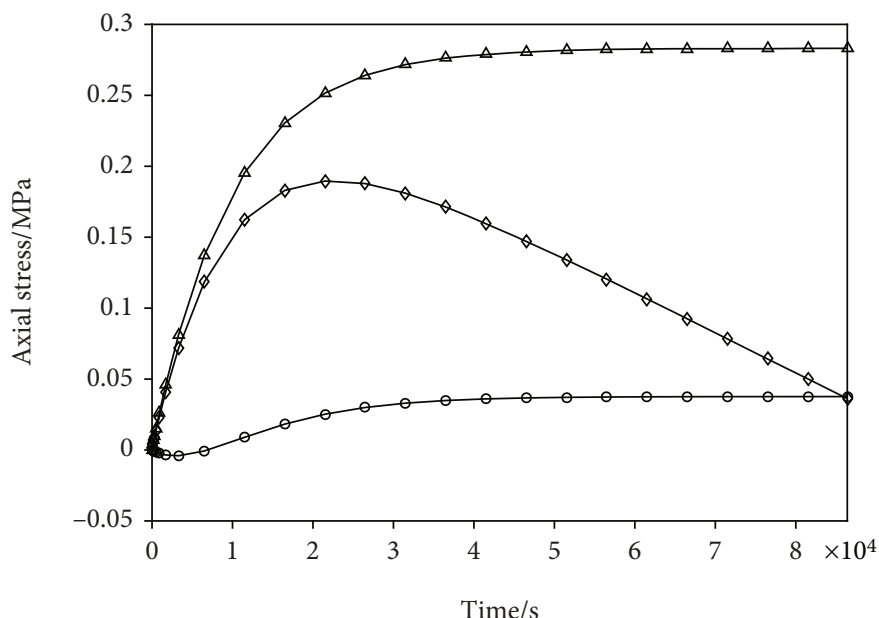

$\triangle$ Normal pressure cure

$\neg$ Initial value of pressure cure

- Optimum value of pressure cure

(c) Axial stress

FIGURE 13: Stress comparison during pressure relief and cooling. 


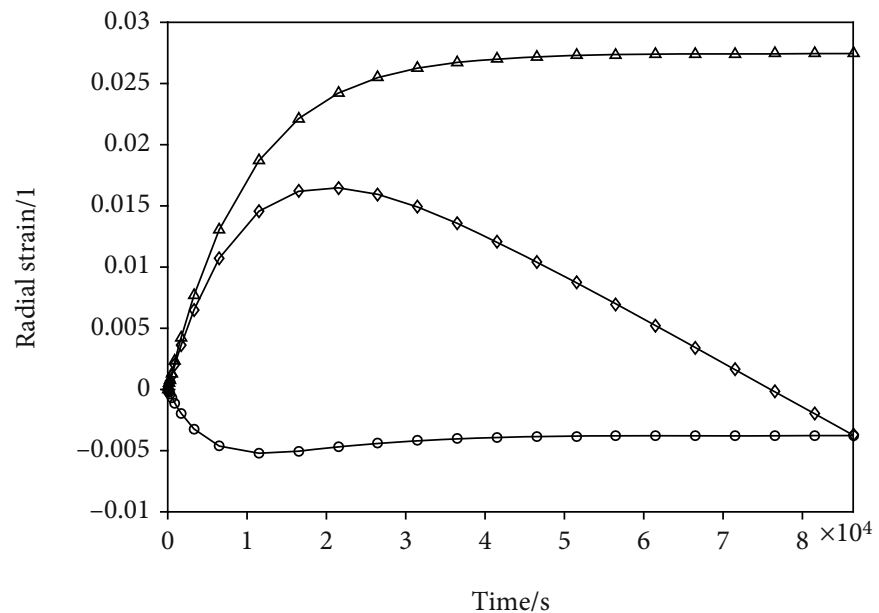

(a) Radial strain

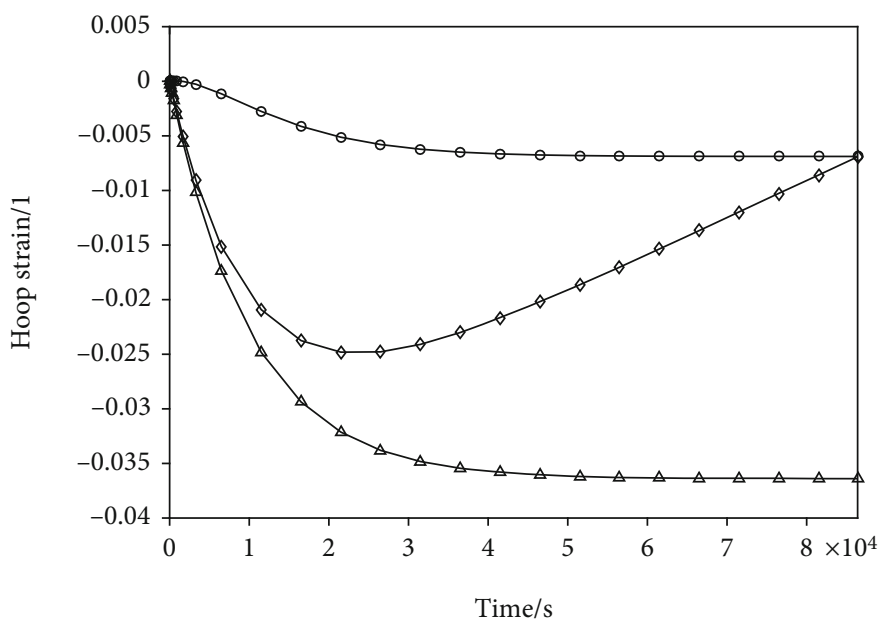

(b) Hoop strain

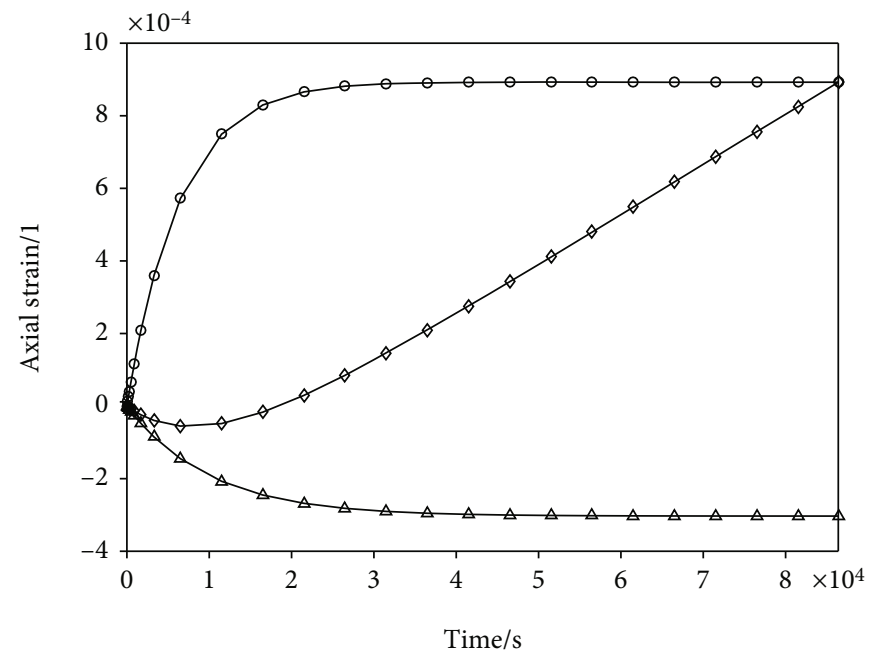

$\triangle$ Normal pressure cure

$\neg$ Initial value of pressure cure

- Optimum value of pressure cure

(c) Axial strain

FIGURE 14: Strain comparison during pressure relief and cooling. 


\section{Conclusions}

The pressure cure casting process was decomposed into two processes, curing and cooling, and the simulation model of the whole process was established. The pressure value, pressure relief curve, and temperature drop curve were optimized with ISIGHT optimization software. According to the research results, the following conclusions can be drawn:

(a) Within the allowable range of theoretical pressure, with the increase of pressure value, the effect of pressure cure is more significant. After cooling, the residual stress and strain of the propellant grain along the three coordinate axes gradually decrease and approach zero. The effect is reversed when the theoretical pressure is exceeded

(b) With the same pressure value and direction, the effect of reducing stress and strain at different positions is different. It shows that different grain structures have different requirements for theoretical pressure

(c) When applying pressure cure during the pouring process of grains, different pressure relief rates and cooling rates have an effect on the stress and strain of the propellant grains. The time at which the maximum stress (strain) in the time history appears is different. When the pressure relief rate has a certain linear relationship with the cooling rate, the effect of pressure cure is the best. Taking the exponential attenuation in this paper as an example, the cooling attenuation coefficient is 8650 , and the pressure relief attenuation coefficient is 6850 , which has a better effect. The use of other types of pressure relief and cooling methods can also be discussed on this basis

\section{Data Availability}

No data were used to support this study.

\section{Conflicts of Interest}

The authors declare that they have no conflicts of interest.

\section{Acknowledgments}

This work was supported by the National Natural Science Foundation of China (Grant Nos. 11872372, 11902348, and 11902350) and Science Project of the National University of Defense Technology (ZK17-02-06).

\section{References}

[1] Y. Wu, Z. Li, and R. Lu, "Simulation and visual tester verification of solid propellant slurry vacuum plate casting," Pyrotechnics, vol. 45, no. 6, pp. 871-879, 2020.

[2] C. A. Chase, "Pioneers in propulsion-a history of CSD, Pratt \& Whitney's solid rocket company," in 46th AIAA/ASME/-
SAE/ASEE Joint Propulsion Conference and Exhibit, Nashville, TN, 2010.

[3] D. A. Hunt, "Computing pressure cure viscoelastic effects in solid propellants," Journal of Spacecraft and Rockets, vol. 9, no. 12, pp. 937-938, 1972.

[4] K. J. Arai, "Research on pressure cure of solid rocket motor," Industry Powder, vol. 43, pp. 360-367, 1982.

[5] L. H. Zong, C. Du, S. Lu, D. Yao, J. Gao, and B. L. Sha, "Simulation on pressure cure of solid rocket motor grain," Journal of Solid Rocket Technology, vol. 38, no. 5, pp. 653-656, 2015.

[6] Z. Liu, E. Quan, Y. B. Chu, R. B. Jin, P. Ren, and L. Q. Chen, "Theoretical and simulation research onpressure cure of solid rocket motor," Journal of Solid Rocket Technology, vol. 42, no. 5, pp. 576-579, 2019, 596.

[7] D. T. Liang, X. F. Jia, Z. Y. Hu, and J. H. Zhang, "Study on curing technology of solid propellant column under pressurization," in 2017 International Symposium on the Advanced Manufacturing Technology for Aerospace Industry, ShenZhen, 2017.

[8] Z. X. Cui, H. Y. Li, Z. B. Shen, and H. R. Cui, "A viscoelastic constitutive model of propellant with pressure cure," Propellants, Explosives, Pyrotechnics, vol. 46, no. 7, pp. 1036-1048, 2021.

[9] H. T. Dong, "Application of ISIGHT in the optimization process of ship seakeeping," Ship Science and Technology, vol. 43, pp. 10-12, 2021.

[10] J. Ren, H. W. Zhu, H. Wang, C. F. Zhao, and J. L. Zhong, "Multi-objective structural optimization of VL seal ring based on Isight," Journal of Physics: Conference Series, vol. 1622, article 012031, 2020.

[11] F. F. Yang, H. Y. Tian, C. X. Yan, C. J. Wu, and D. Q. Mu, "Optimization of the lens structure based on the line of sight jitter error in Isight environment," Infrared and Laser Engineering, vol. 48, pp. 223-230, 2019.

[12] S. T. Ding, H. X. Sun, and G. Li, "Control effect study on thermal boundary loading in optimization design of turbine disk," Journal of Aerospace Power, vol. 31, pp. 2731-2737, 2016.

[13] L. Wang, Z. Yang, D. J. Zhen, B. X. Zan, and Q. C. Cai, "Multi parameter dynamic optimization design of man-gun system based on Isight," Journal of Ordnance Equipment Engineering, vol. 41, pp. 55-60, 2020.

[14] Q. W. Zhang, "Lightweight design of arm frame of chain bucket ship unloader based on Isight," Hoisting and Conveying Machinery, vol. 69-73, p. 87, 2019.

[15] R. X. Chen, Design and Research of Solid Rocket Motor, China Aerospace Publishing House, Beijing, 1991.

[16] L. Li, Shape Improvement and Optimization of Solid Rocket Motor Grain Based on Structural Integrity Analysis, National University of Defense Technology, 2011.

[17] J. F. Cao, X. C. Wang, and L. Kong, Application of Python Language in ABAQUS, China Machine Press, Beijing, 2011.

[18] W. D. Zhang, J. L. Fan, L. Chen, and Y. B. Lv, "Crack growth simulation based on ABAQUS secondary development," Journal of Mechanical Strength, vol. 40, pp. 1467-1472, 2018.

[19] P. T. Liu, "Finite element simulation of ultrasonic vibration turning and parameter optimization," Tool Engineering, vol. 51, pp. 31-36, 2017. 